\title{
Intestinal Transport of Cystine and Cysteine in Man: Evidence for Separate Mechanisms *
}

\author{
Leon E. Rosenberg, $\dagger$ John C. Crawhall, $\ddagger$ and Stanton Segal \\ (From the Metabolism Branch, National Cancer Institute, and the Clinical Endocrinology \\ Branch, National Institute of Arthritis and Metabolic Diseases, National \\ Institutes of Health, Bethesda, Md.)
}

\begin{abstract}
Summary. Cystine and cysteine are transported by energy-dependent, mediated processes in human gut. When either of these amino acids is transported, only cysteine is recovered intracellularly, indicating that cystine is reduced to cysteine after achieving an intracellular location. In contrast to results with cystine, cysteine uptake is not defective in gut from cystinuric patients, nor do lysine and arginine compete with cysteine for transport. It is, therefore, concluded that cystine and cysteine are transported by different mechanisms, and that only the cystine transport mechanism is defective in cystinuria.
\end{abstract}

\section{Introduction}

Recent studies of the nature of the biochemical defect in cystinuria have stressed renal tubular and intestinal transport mechanisms for cystine (1-4). Although cysteine has been demonstrated in significant quantities in blood plasma and urine (5) and has been shown to be decreased in concentration in plasma from cystinuric subjects (6), little information regarding transport or intracellular utilization of this reduced monomer of cystine has been presented. This paucity of information has been due, in large measure, to the great difficulty in keeping cysteine reduced under physiologic or near physiologic incubation conditions. Recently, however, Crawhall and Segal have reported methods by which this difficulty can be overcome (7).

In the present studies transport of cystine and cysteine by intestinal mucosa from normal and cystinuric subjects has been investigated. The data indicate that cysteine is transported by a mechanism distinct from that for cystine and that

* Submitted for publication June 20, 1966; accepted September 15, 1966.

† Address requests for reprints to Dr. Leon E. Rosenberg, Dept. of Medicine, Yale University School of Medicine, New Haven, Conn.

$¥$ Visiting Scientist, National Institutes of Health; on leave from the Medical Professional Unit, St. Bartholomews Hospital, London, England. cysteine transport is not defective in gut mucosa from cystinuric subjects.

\section{Methods}

Peroral biopsies of jejunal mucosa were obtained with a Rubin tube as described previously (2). A total of 25 biopsies was obtained from five normal subjects and eight patients with documented cystinuria. Each cystinuric patient excreted marked excesses of cystine, lysine, arginine, and ornithine in the urine and had formed several renal calculi composed of cystine.

Uptake of L-cystine- ${ }^{85} \mathrm{~S}$ ( 0.06 mmole per $\left.\mathrm{L}\right)$ by jejunal mucosa was studied as described previously (2). In studies of cysteine transport, the L-cystine $-{ }^{25} \mathrm{~S}$ was converted quantitatively to $\mathrm{L}$-cysteine- ${ }^{35} \mathrm{~S}$ by preincubating the cystine (dissolved in Krebs-Ringer bicarbonate buffer, $\mathrm{pH}$ 7.4) in $2 \mathrm{mM}$ dithiothreitol (DTT) for 10 minutes at room temperature (7). The DTT reduced all of the cystine to cysteine and maintained the reduction throughout the duration of incubation used in these studies (up to 45 minutes). The gut mucosal specimens were placed in 25-ml Erlenmeyer flasks containing either cystine or cysteine, gassed for 30 seconds with $95 \% \quad \mathrm{O}_{2}-5 \% \quad \mathrm{CO}_{2}$, sealed, and incubated in a Dubnoff metabolic shaker at $37^{\circ} \mathrm{C}$ for 5 to 45 minutes. In studies with tissue from four normal and five cystinuric subjects paired data were collected by incubating one-half of the biopsy sample with cystine and the second half with cysteine. At the conclusion of the incubation, the tissues were removed from the flasks, dipped twice into isotonic saline, blotted, weighed, and plunged into ground glass tubes containing $0.5 \mathrm{ml}$ of $20 \mathrm{mM} \mathrm{N}$-ethyl maleimide (NEM) in $0.1 \mathrm{mM}$ phosphate buffer, $\mathrm{pH}$ 7.4. Smyth, Nagamatsu, and Fruton (8) showed that NEM reacts rapidly with cysteine 


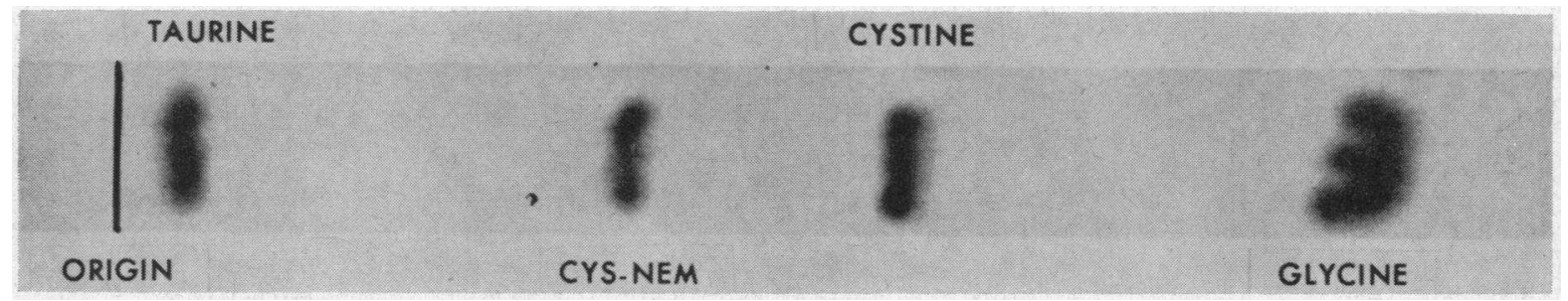

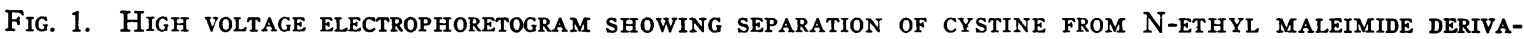
TIVE OF CYSTEINE (CYS-NEM). Locations of glycine and taurine spots are presented for reference purposes. Conditions of the electrophoretic separation are as follows: buffer, $6.8 \%$ formic acid; duration, 2 hours; temperature, $45^{\circ} \mathrm{C}$; potential, $4,000 \mathrm{v}$; current, $250 \mathrm{ma}$.

to form the stable derivative, 2-(L-2-amino-2-carboxyethylthio)-N-ethyl succinimide (cys-NEM). Recently Crawhall and Segal (9) utilized this reaction to distinguish between intracellular cystine (which does not react with NEM) and cysteine in kidney cortex slices from rats and humans. The tissue was then homogenized for 45 seconds with a motor-driven Potter-Elvehjem homogenizer; $0.5 \mathrm{ml}$ of $10 \%$ trichloroacetic acid (TCA) was then aded to precipitate tissue proteins, which were separated by centrifugation. Two-tenths-ml samples of the incubation medium were also placed in tubes containing $1.0 \mathrm{ml}$ of $20 \mathrm{mM} \mathrm{NEM}$ and treated in a manner identical to that described for the mucosal specimens.

Radioisotopic analysis of the medium and tissue supernatant was performed by two methods. Total ${ }^{35} \mathrm{~S}$ content was estimated by counting $0.2-\mathrm{ml}$ samples of the medium and tissue supernatant in a liquid scintillation spectrometer as described previously (2). Additional samples of medium and tissue supernatant from which TCA had been extracted with ether were spotted on Whatman 3-mm paper and run for 2 hours in a Gilson high voltage electrophorator $(4,000 \mathrm{v}, 250 \mathrm{ma})$ in $6.8 \%$ formic acid in water. Suitable standards of cystine and the cys-NEM were run concurrently with all unknowns. The paper strips were then marked according to the standards, cut into small squares, placed in counting vials, and counted in a liquid scintillation spectrometer as described previously (9). A photograph of a typical separation of cystine from cys-NEM by high voltage electrophoresis is shown in Figure 1.

The distribution ratio, defined in these experiments as the ratio of the concentration of ${ }^{35} \mathrm{~S}$ per milliliter of intracellular fluid to that per milliliter of medium, was calculated as described previously (2). The quantities of isotopically labeled cystine or cys-NEM identified by high voltage electrophoresis were expressed either as counts per minute or as per cent of total recovered radioactivity. Total recovery of radioactivity exceeded 85 to $90 \%$ of the applied counts. Statistical analyses were performed by using Student's $t$ test.

Cystine ${ }^{35} \mathrm{~S}^{1}$ (initial SA $24.4 \mathrm{mc}$ per mmole), dithiothreitol, ${ }^{2}$ and $\mathrm{N}$-ethyl maleimide ${ }^{2}$ were obtained commercially

1 Schwartz Bioresearch, Inc., Orangeburg, N. Y.

2 California Biochemicals Corp., Los Angeles, Calif.

TABLE I

Intracellular concentration of cystine and cysteine in gut mucosa from normal and cystinuric subjects*

\begin{tabular}{|c|c|c|c|c|}
\hline \multirow[b]{2}{*}{ Subject } & \multirow[b]{2}{*}{ Substrate amino acid } & \multirow{2}{*}{$\begin{array}{l}\text { 25S dis- } \\
\text { tribution } \\
\text { ratiof }\end{array}$} & \multicolumn{2}{|c|}{ Tissue counts per minutef } \\
\hline & & & Cystine & Cys-NEM \\
\hline $\begin{array}{l}\text { Normal } \\
\text { F.W. }\end{array}$ & $\begin{array}{l}\text { Cystine }(0.06 \text { mmole per } \mathrm{L}) \\
\text { Cysteine }(0.06 \text { mmole per } \mathrm{L})\end{array}$ & $\begin{array}{l}4.2 \\
9.6\end{array}$ & $\begin{array}{l}8 \\
7\end{array}$ & $\begin{array}{l}426 \\
932\end{array}$ \\
\hline $\begin{array}{c}\text { Cystinuric } \\
\text { E.B. } \\
\text { D.B. } \\
\text { S.M. }\end{array}$ & $\begin{array}{l}\text { Cystine }(0.06 \text { mmole per } L) \\
\text { Cysteine }(0.06 \text { mmole per } L) \\
\text { Cystine }(0.04 \text { mmole per } L) \\
\text { Cysteine }(0.04 \text { mmole per } L) \\
\text { Cystine }(0.06 \text { mmole per } L)\end{array}$ & $\begin{array}{r}2.1 \\
14.1 \\
0.7 \\
8.2 \\
1.5\end{array}$ & $\begin{array}{l}22 \\
10 \\
43 \\
29 \\
43\end{array}$ & $\begin{array}{r}1,124 \\
6,590 \\
230 \\
1,637 \\
340\end{array}$ \\
\hline
\end{tabular}

* All tissues were incubated for 30 minutes in Krebs bicarbonate buffer, $\mathrm{pH} 7.4$, at $37^{\circ} \mathrm{C}$.

$\dagger$ Defined as the ratio of the counts per minute per milliliter of intracellular fluid to the counts per minute per milliliter of medium.

$\ddagger$ Obtained from radioisotopic monitoring of high voltage electrophoretograms as described in Methods. Electrophoresis of the incubation media revealed that virtually $100 \%$ of the recovered radioactivity was present in the form of the appropriate substrate amino acid. The specific activity of the cystine- ${ }^{-35} \mathrm{C}$ varied considerably during the course of these experiments as did tissue weight; thus, only the distribution ratios between subjects can be compared meaningfully, not the tissue counts per se. The tissue counts are presented to demonstrate the differences in tissue cystine and cysteine for any given subject. Cys-NEM $=\mathrm{N}$-ethyl maleimide derivative of cysteine. 


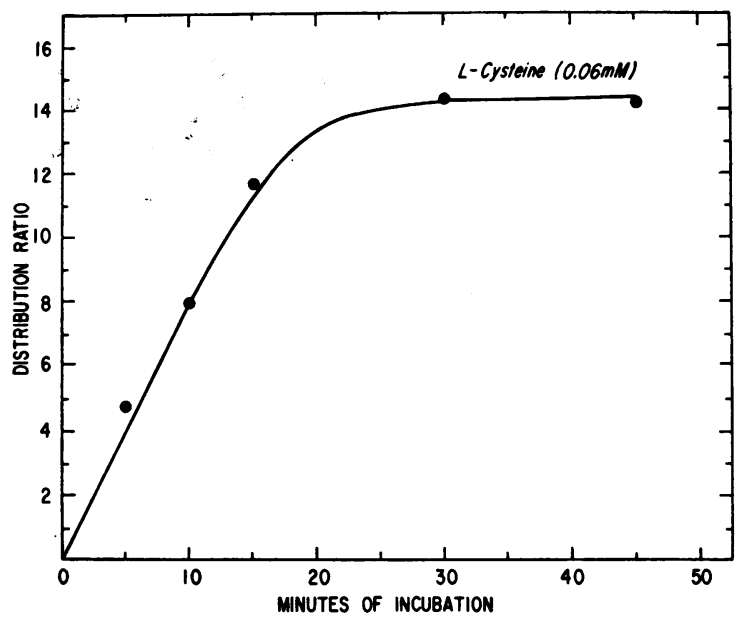

Fig. 2. TIMe COURSE OF UPTAKe OF CYSTEINE- ${ }^{35} \mathrm{~S}(0.06$ MMOLE PER L) BY NORMAL GUT MUCOSA. Data represent means of duplicate observations.

as were all unlabeled amino acids. ${ }^{3}$ L-Amino acids were used throughout.

\section{Results}

Conversion of cystine to cysteine by gut mucosa. When mucosa from normal and cystinuric subjects was incubated with cysteine, virtually all of the tissue and medium radioactivity was recovered as cysteine in the form of the cys-NEM derivative (Table I). However, very different results were noted when cystine was the substrate amino acid. All of the medium radioactivity remained as cystine, but, as shown in Table I, almost no cystine was found in the tissue, all of the radioactivity being accounted for as cysteine. This significant point was overlooked in previous investigations from these laboratories $(2,10)$ because tissues were equilibrated with boiling distilled water or trichloroacetic acid rather than NEM, thus favoring oxidation of cysteine to cystine. Hence, the distribution ratios to be presented for cysteine uptake represent chemically identical species outside and inside the mucosal cells, but such is not the case for cystine where conversion to cysteine has occurred either during the transport process or after the amino acid has achieved an intracellular location. Evidence to be presented subsequently favors the latter alternative.

Evidence for mediated transport of cysteine. As noted in Figure 2, cysteine was rapidly taken up

${ }^{3}$ Nutritional Biochemicals Co., Cleveland, Ohio. by gut mucosa to concentrations much in excess of that in the incubation medium. Uptake was linear for 15 minutes, and equilibrium conditions were reached after 30-minute incubations. Cysteine uptake was distinctly impaired under anaerobic conditions and when the sodium ion was removed from the incubation medium (Table II). Thus, cysteine, like other amino acids (2), is accumulated in gut mucosa by energy-dependent mechanisms. Furthermore, as the concentration of cysteine in the medium was increased, the rate of accumulation approached a maximal value, indicating the presence of a saturable mechanism. These data, plotted by the double reciprocal method, are shown in Figure 3 and yield an apparent Michaelis constant $(\mathrm{Km})$ of 1.4 mmoles per L.

Uptake of cystine and cysteine in cystinuria. As shown previously, cystine uptake by gut mucosa from type I cystinuric subjects (4) was distinctly impaired or absent (ratios of approximately unity) when compared to results with controls (Figure 4). However, as seen in Figure 4, no difference between normal and cystinuric subjects was found when cysteine, rather than cystine, was used as the substrate in the transport studies. The equilibrium distribution ratios for cysteine far exceeded those for cystine. This difference reflected true variations in the transport of these materials rather than effects of the DTT, since uptake of glycine and lysine by gut mucosa from normal subjects was unaffected by concentrations of DTT equal to those used in the present studies.

Absence of competition between cysteine and dibasic amino acids. We have demonstrated previously that cystine uptake by normal gut mucosa is

TABLE II

Influence of anaerobic conditions and deletion of medium $\mathrm{Na}^{+}$on cysteine uptake*

\begin{tabular}{lc}
\hline \hline Conditions & $\begin{array}{c}\text { Distribution } \\
\text { ratio }\end{array}$ \\
\hline Control & 13.0 \\
Anaerobic & 7.8 \\
$\mathrm{Na}^{+}$-free & 2.7. \\
\hline
\end{tabular}

* Tissues were incubated with cysteine ${ }^{35} \mathrm{~S}(0.06 \mathrm{mmole}$ per L) for 30 minutes at $37^{\circ} \mathrm{C}$. Anaerobic conditions were achieved by gassing the buffer and atmosphere with $95 \%$ $\mathrm{N}_{2}-5 \% \mathrm{CO}_{2}$. In the sodium-free buffer, isosmolar conditions were maintained by substitution with Tris- $\mathrm{HCl}$. The results represent the mean of four observations in two normal subjects. The inhibitory effects of sodium removal and anaerobiosis were both highly statistically significant $(\mathrm{p}<0.01)$ 


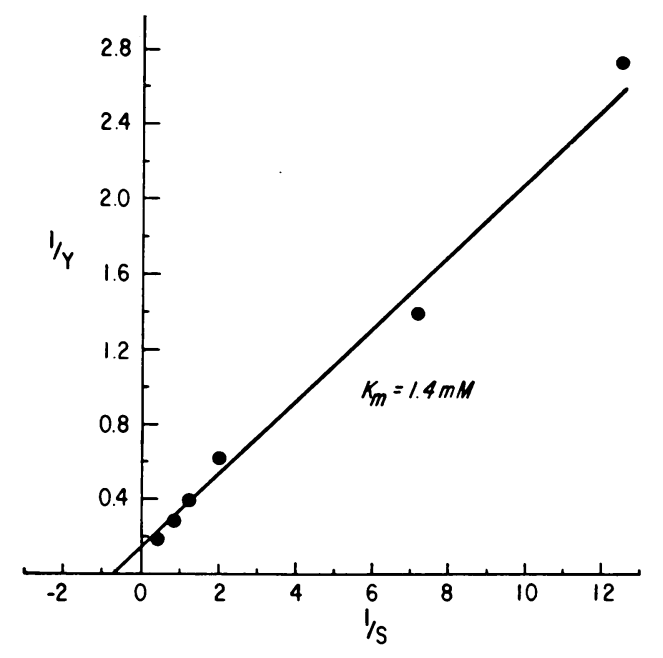

Fig. 3. Dolble Reciprocal plot of Cysteine ctpake BY XORMAL GUT MICCOSA. Tissues were incubated for 5 minutes at $37^{\circ} \mathrm{C}$. S refers to substrate concentration (millimoles per liter), and $\mathrm{Y}$ denotes velocity of uptake expressed in millimoles per liter per 5 minutes corrected for diffusion (2). $\mathrm{Km}=$ apparent Michaelis constant, or in this case the concentration of cysteine yielding half maximal uptake velocity.

inhibited by lysine and arginine (2), suggesting that these anino acids share a common transport mechanism in this tissue. In contrast, however, cysteine uptake under comparable conditions was not significantly affected by either lysine or arginine, even when these amino acids were present in concentrations 8 to 10 times that of cysteine (Table III).

\section{Discussion}

These studies demonstrate that cystine is reduced to cysteine during or after transport across the gut cell membrane. If this reductive process occurred during the actual transport step, both cystine and cysteine would be transported as cysteine. Two types of evidence presented in this

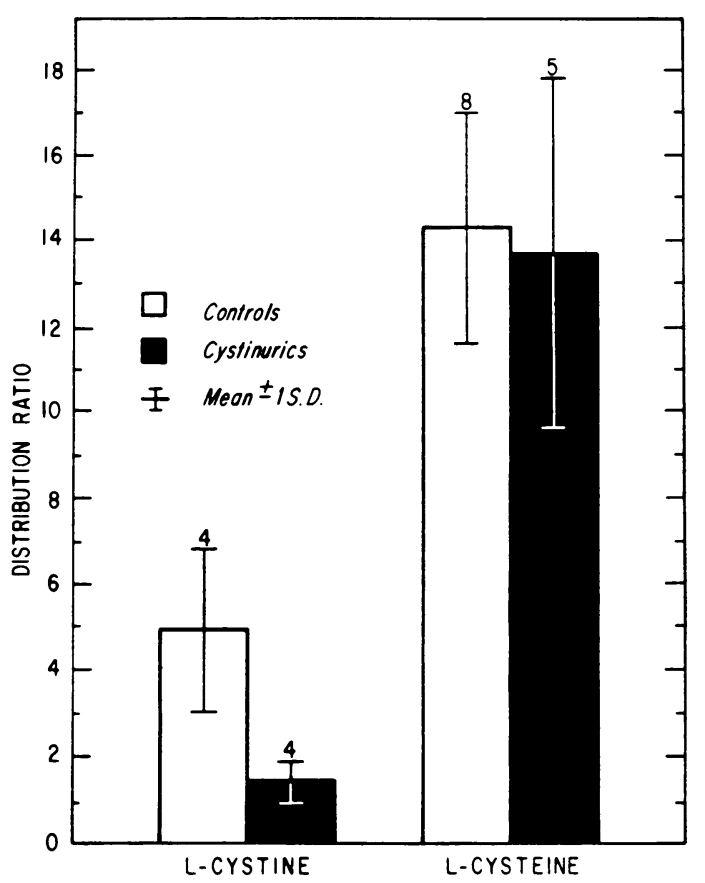

Fig. 4. LPtake of CYSTINE (0.06 MMOLE PER L) AND CYSTEINE (0.06 MMOLES PER L) BY GLT MLCOSA FROM XORMAL AND CYSTINCRIC SLBJECTS. Thirty-minute incubations were used throughout. The value in parentheses indicates the number of observations.

report make this hypothesis seem quite unlikely. First, cystine uptake is defective in cystinuric gut, whereas cysteine accumulation is normal. It could be argued that this results from a defect in the mechanism by which cystine is reduced to cysteine rather than to a transport abnormality per se, but no such defect was found in gut from two cystinuric subjects, both of whom reduced cystine to cysteine intracellularly despite marked impairment in total uptake. Second, lysine and arginine, which have been shown to inhibit cystine uptake by human gut (2), were completely without effect on cysteine transport. These results

TABLE III

Influence of lysine and arginine on cysteine uptake by normal gut mucosa*

\begin{tabular}{|c|c|c|c|}
\hline Substrate & Inhibitor & $\begin{array}{l}\text { Distribution } \\
\text { ratio }\end{array}$ & $\begin{array}{l}\text { Significance } \\
\text { of difference } \\
\text { from control }\end{array}$ \\
\hline $\begin{array}{l}\text { L-Cysteine } \\
\text { (0.06 mmole per L) }\end{array}$ & $\begin{array}{l}\text { None } \\
\text { L-Arginine ( } 0.8 \text { mmole per I-) } \\
\text { L-Lysine ( } 0.8 \text { mmole per L) }\end{array}$ & $\begin{array}{l}6.6 \pm 0.8(5) \\
6.5 \pm 2.0(5) \\
6.1 \pm 2.0(4)\end{array}$ & $\begin{array}{l}p>0.5 \\
p>0.4\end{array}$ \\
\hline
\end{tabular}

* Tissues were incubated for 10 minutes at $37^{\circ} \mathrm{C}$.

$\dagger$ Values represent mean $\pm 1 \mathrm{SD}$. Value in parentheses refers to the number of observations. 
strongly suggest that cystine and cysteine are transported by two different mechanisms and that conversion of cystine to cysteine takes place intracellularly. The chemical or enzymatic reactions responsible for this conversion are unknown at present.

Recent reports by London and Foley $(11,12)$ and by Rosenberg, Durant, and Holland (6) showed that type I cystinuric patients (4) were unable to absorb cystine after oral loading, but that cysteine was absorbed normally. The present results provide in vitro confirmation of these findings and indicate that the intestinal transport defect in cystinuria, known to involve cystine and the dibasic amino acids, does not extend to cysteine absorption or transport.

Neil (13) studied absorption of cystine and cysteine from rat intestine using in vitro perfusion and in vitro everted sac techniques. He found that cysteine was more rapidly absorbed than cystine when the two amino acids were perfused separately. His in vitro work was limited to studies of cystine transport because the experimental conditions used ( $\mathrm{pH} 7.4$, Krebs buffer) ensured rapid oxidation of all cysteine to cystine. No attempt was made to determine the chemical form of the sulfur amino acids within the intestinal cells; thus the experiments are not comparable in design or technique to those reported here.

\section{References}

1. Fox, M., S. Thier, L. E. Rosenberg, W. Kiser, and S. Segal. Evidence against a single renal trans- port defect in cystinuria. New Engl. J. Med. 1964, 270, 556.

2. Thier, S. O., S. Segal, M. Fox, A. Blair, and L. E. Rosenberg. Cystinuria: defective intestinal transport of dibasic amino acids and cystine. J. clin. Invest. 1965, 44, 442.

3. McCarthy, C. F., J. L. Borland, Jr., H. J. Lynch, Jr., E. E. Owen, and M. P. Tyor. Defective uptake of basic amino acids and L-cystine by intestinal mucosa of patients with cystinuria. J. clin. Invest. $1964,43,1518$.

4. Rosenberg, L. E., S. Downing, J. L. Durant, and S. Segal. Cystinuria: biochemical evidence for three genetically distinct diseases. J. clin. Invest. 1966, 45, 365.

5. Brigham, M. P., W. H. Stein, and S. Moore. The concentrations of cysteine and cystine in human blood plasma. J. clin. Invest. 1960, 39, 1633.

6. Rosenberg, L. E., J. L. Durant, and J. M. Holland. Intestinal absorption and renal extraction of cystine and cysteine in cystinuria. New Engl. J. Med. 1965, 273, 1239.

7. Crawhall, J. C., and S. Segal. Dithiothreitol in the study of cysteine transport. Biochim. biophys. Acta. (Amst.) 1966, 121, 215.

8. Smyth, D. G., A. Nagamatsu, and J. S. Fruton. Some reactions of $\mathrm{N}$-ethyl-maleimide. J. Amer. chem. Soc. 1960, 82, 4600.

9. Crawhall, J. C., and S. Segal. The intracellular cysteine/cystine ratio in kidney cortex. Biochem. J. 1966, 99, 19c.

10. Rosenberg, L. E., S. J. Downing, and S. Segal. Competitive inhibition of dibasic amino acid transport in rat kidney. J. biol. Chem. 1962, 237, 2265.

11. London, D. R., and T. H. Foley. Cystine metabolism in cystinuria. Clin. Sci. 1965, 29, 129.

12. Foley, T. H., and D. R. London. Cysteine metabolism in cystinuria. Clin. Sci. 1965, 29, 549.

13. Neil, M. W. The absorption of cystine and cysteine from rat small intestine. Biochem. J. 1959, 71, 118. 